\title{
USES OF HYPERBARIC OXYGEN THERAPY: A REVIEW
}

Farheen Ustad, Fareedi Mukram Ali, Tanveer Ustad, Vinit Aher, Prasant M. C,

Harshal Suryavanshi
1. Lecturer, Department of Oral and Maxillofacial Surgery. King Khalid University Abha.
2. Reader, Department of Oral and Maxillofacial Surgery. SMBT Dental College, Sangamner Taluka.
3. Senior Resident, Department of Urology, St. Johns Medical College Hospital, Bangalore.
4. Senior Lecturer, Department of Oral and Maxillofacial Surgery. Sangamner Taluka.
5. Professor \& HOD, Department of Oral and Maxillofacial Surgery. RKDF Dental College, Bhopal.
6. Senior Lecturer, Department of Oral and Maxillofacial Surgery. YMT Dental College, Nayi Mumbai

\section{CORRESPONDING AUTHOR}

Dr. Fareedi Mukram Ali, Reader, Dept of Oral \& Maxillofacial Surgery, Sangamner Taluka, Ahmednagar Dist, Maharashtra, E-mail: faridi17@rediffmail.com Ph: 00919326325156

ABSTRACT: In the last three decades great strides in Hyperbaric Oxygen research has raised the value of this unique therapy. Studies have expanded the list of conditions usefully treated with compressed oxygen. Despite the promising experimental and clinical data, the major criticism to most HBO studies has been the lack of controlled prospective analysis for its use. This article discusses the use of HBO, including staffing and equipment considerations, side effects and reviews the published experience in this subject.

KEYWORDS: hyperbaric oxygen therapy, HBO, uses of HBO.

INTRODUCTION: HBO therapy was initially used to treat patients involved in diving accidents or with decompression sickness. However, its indications have increased over the past few decades. Currently, there are twelve indications for HBO therapy approved by the Undersea and Hyperbaric Medical Society (UHMS) in the United States. ${ }^{1}$ There are, however, over a hundred indications internationally, although most of them have not been proven by controlled studies. The committee on hyperbaric medicine defines hyperbaric oxygen therapy as "A mode of medical treatment in which the patient is entirely enclosed in a pressure chamber and breathes $100 \%$ oxygen at a pressure greater than 1 atmosphere absolute (ATA)". ATA is the units of pressure and 1 ATA is equal to $760 \mathrm{~mm}$ of mercury or pressure at sea level. ${ }^{1} \mathrm{As}$ with most areas of medicine, in hyperbaric medicine there is a constant struggle to balance enthusiasm for progress in the field with the need to apply it on the basis of established evidence.The lack of sound scientific evidence of the efficacy of HBO has bred uncertainty in the wider medical community regarding its legitimacy.

PHYSIOLOGICAL BASIS: The arterial partial pressure of 02 is $100 \mathrm{~mm} \mathrm{Hg}, \mathrm{Hb}$ is $95 \%$ saturated and $100 \mathrm{ml}$ of blood carries $19 \mathrm{ml}$ of 02 in combination with $\mathrm{Hb}$ and $0.32 \mathrm{ml}$ dissolved in plasma. If the inspired 02 concentration is increased to $100 \%$, 02 combined with $\mathrm{Hb}$ can increase to a maximum of $20 \mathrm{ml}$ when the $\mathrm{Hb}$ is $100 \%$ saturated and the amount of 02 dissolved in plasma may increase to $2.09 \mathrm{ml}$. During $\mathrm{HBO}$ in addition to the $\mathrm{Hb}$ which is $100 \%$ saturated the amount of 02 carried in solution will increase to $4.4 \mathrm{ml} \%$ at a pressure of 2 ATA to $6.8 \mathrm{ml} \%$ at 3 ATA which is almost sufficient to supply the resting total oxygen requirement of many tissues 
without a contribution from oxygen bound to hemoglobin. Itis this increased oxygen in plasma which is responsible for most of the beneficial effects of hyperbaric oxygen ${ }^{2}$

HISTORY OF HYPERBARIC OXYGEN THERAPY: The first pressurized room used to treat health problems was built by an Englishman named Henshaw in 1662.3in1788; hyperbaric air was put to large scale use in a diving bell for underwater industrial repairs of an English bridge. The first deep sea diving suit, invented in 1819 by August Siebe, used compressed air supplied to the helmet for generous underwater movement. ${ }^{4} \mathrm{Dr}$. John S. developed the first diving tables for the Royal Navy. His legacy gives him the title "Father of Oxygen Therapy" and physicians continue in his line of work to this day. ${ }^{4}$ In 1918 Dr. Orval Cunningham built the world's largest functional hyperbaric chamber, a 64' steel sphere "hyperbaric medical hotel" with five floors of living space after he found that denser air helped people fight infection suffering from flu. The Great Depression in the 1930's ended his project and the giant chamber was scrapped for the war effort in the 1940's. ${ }^{5}$ The Hyperbaric Oxygen Committee was developed by the UHMS in 1976 to oversee the ethical practice of hyperbaric medicine. ${ }^{5}$

\section{THERAPEUTIC EFFECTS OF HBO THERAPY:}

Therapeutic effects of HBO can be attributed to its mechanical or hyperoxygenation effects as shown in the table

\begin{tabular}{|l|l|}
\hline Therapeutic effects & Mechanism \\
\hline Reduces bubble size & Direct mechanical effect. \\
\hline Immune stimulation & $\begin{array}{l}\text { Restores WBC function, enhances phagocytic } \\
\text { capabilities and neutrophil mediated killing of } \\
\text { bacteria. }\end{array}$ \\
\hline Neovascularization & $\begin{array}{l}\text { Augmentation of fibroblastic activity which } \\
\text { promotes capillary growth. }\end{array}$ \\
\hline Reduces edema and tissue swelling & $\begin{array}{l}\text { Fyper oxygenation. anaerobic organisms such as } \\
\text { Clostridiwelchii, } \\
\text { and also inhibits the growth of aerobic } \\
\text { bacteria at pressures } \\
\text { greater than 1.3 ATA. }\end{array}$ \\
\hline
\end{tabular}

ADMINISTRATION: HBO therapy can be given in a monoplace chamber in which a single patient is placed in a chamber pressurized with $100 \%$ oxygen or it can be given in a multiplace chamber where many patients can be treated at the same time. To be effective, hyperbaric oxygen must be inhaled in the atmosphere or through an endotracheal tube in a monoplace chamber and in multiplace chamber masks, tight-fitting hoods, or endotracheal tubes can be used. Monoplace chambers are the most common type of chamber used due to their portability, minimal personnel requirements and low cost. ${ }^{6}$

Time: The duration of single treatments varies from 45 minutes for carbon monoxide poisoning to almost 5 hours for some severe decompression disorders. For treatment of wounds - most protocols average 90 minutes for each of 20 to 30 treatments.

Journal of Evolution of Medical and Dental Sciences/Volume1/Issue5/November-2012Page-893 
GENERAL EQUIPMENT CONSIDERATIONS: All equipment used inside hyperbaric chambers must adhere to the guidelines of the National Fire Protection Association (NFPA).$^{7}$ Chamber fires result in catastrophic consequences. ${ }^{8}$ The primary cause of mishaps is the introduction of prohibited items into the chambers, specifically when chamber personnel do not adhere to NFPA fire safety rules. Equipment inside chambers must be intrinsically electrically safe, follow NFPA guidelines, and be tested for the pressures to which they will be exposed. ${ }^{7}$

HYPERBARIC CHAMBER SELECTION, LOCATION AND STAFFING: Hyperbaric oxygen can be offered to critically ill patients inmonoplace and multiplace chamber. Monoplace chambers can be located inside the intensive care unit, where they can be staffed by ICU personnel and are then an extension of the ICU.9, ${ }^{10}$ However; hands-on care cannot be provided to a patient inside a monoplace chamber. Although multiplace chambers do allow hands-on care, experienced staff must be available inside the chamber. Because most hyperbaric chambers are not located within or adjacent to the ICU, the potential benefits of HBO2 to a critically ill patient must be balanced by the risks from transporting the patient as well as the risks from HBO. ${ }^{11,12}$ Personnel working as inside attendants of multiplace chambers must be medically suitable for hyperbaric exposure (e.g., able to equalize ears, no claustrophobia, no pulmonary or cardiac disease, etc). Staff supporting critically ill patients during HBO2 could include Certified Hyperbaric Registered Nurses, physicians; critical care respiratory therapists, and paramedics.

INDICATIONS: The following indications are approved uses of hyperbaric oxygen therapy as defined by the Hyperbaric Oxygen Therapy Committee.

1. Air or Gas Embolism

2. Carbon Monoxide Poisoning

Carbon Monoxide Poisoning Complicated By Cyanide Poisoning

3. Clostridial Myositis and Myonecrosis (Gas Gangrene)

4. Crush Injury, Compartment Syndrome and Other Acute Traumatic Ischemias

5. Decompression Sickness

6. Arterial Insufficiencies:

Central Retinal Artery Occlusion

Enhancement of Healing In Selected Problem Wounds

7. Severe Anemia

8. Intracranial Abscess

9. Necrotizing Soft Tissue Infections

10. Osteomyelitis (Refractory)

11. Delayed Radiation Injury (Soft Tissue and Bony Necrosis)

12. Compromised Grafts and Flaps

13. Acute Thermal Burn Injury

14. Idiopathic Sudden Sensorineural Hearing Loss.

\section{USES OF HBO}

ARTERIAL GAS EMBOLISM: Arterial gas embolism, occurs when air bubbles in the circulation. There are many causes, including mechanical ventilation; central line placement, haemodialysis, severe diving injury and pulmonary barotrauma. ${ }^{13}$ The bubbles cause tissue deformation and vessel occlusion, impairing tissue perfusion and oxygenation. Biochemical effects at the blood- 
gas interface cause endothelial damage, changes in haemostasis and activation of leukocytes. ${ }^{14}$ Clinical symptoms include muscle and joint pain, arrhythmias, ischemia, confusion, focal neurological deficits and loss of consciousness.

\section{RATIONALE OF TREATMENT WITH HBO:}

-HBO reduces bubble size in accordance with Boyle's law-at 3ATA, bubble volume is reduced by about two-thirds. ${ }^{15}$

-Hyperoxia increases the diffusion gradient with the embolized gas, moving gas into solution where it can be metabolized. ${ }^{16}$

HBO is widely accepted as the only life-saving treatment, UHMS suggests maximal benefit with $100 \%$ oxygen at 2.8 ATA, and repeated treatments until no further improvement is seen, typically after no more than 5-10 treatments. ${ }^{17} 19$ patients in the USA with iatrogenic cerebral arterial gas embolism, showed significant improvement in symptoms with HBO treatment, but the loophole in the study was the control group and end-points were not clearly defined. ${ }^{18} \mathrm{HBO}$ is most effective when initiated early, but can be successful after hours or even days. ${ }^{17}$

CARBON MONOXIDE POISONING: Loss of consciousness (syncope, seizures, and coma), neurologic deficits, pulmonary edema, myocardial ischemia, and severe metabolic acidosis are the most common symptoms of carbon monoxide poisoning caused primarily from smoke inhalation and suicide attempts. Less severely poisoned patients may have headache, nausea, and other constitutional symptoms. All victims of carbon monoxide poisoning are at risk for delayed neuropsychological sequelae.CO combines preferentially with hemoglobin to produce $\mathrm{COHb}$, displacing oxygen and reducing systemic arterial oxygen (02) content. CO binds reversibly to hemoglobin with an affinity 200- 230 times that of oxygen. ${ }^{19}$ consequently, relatively minute concentrations of the gas in the environment can result in toxic concentrations in human blood. Toxicity includes decrease in the oxygen carrying capacity of blood and alteration of the dissociation characteristics of oxyhemoglobin. It also causes decrease in cellular respiration by binding with cytochrome a3 and binding to myoglobin, which leads to myocardial and skeletal muscle dysfunction. ${ }^{19}$

The rationale for the use of HBO:

- HBO induces cerebral vasoconstriction, which may reduce intracranial pressure and cerebral edema. ${ }^{20}$

- HBO results in more rapid dissociation of CO from respiratory cytochromes..$^{20}$

- HBO may antagonize the oxidative injury that occurs after CO poisoning. ${ }^{20}$

Thom has demonstrated that oxygen at 3 ATA, but not at 1 ATA prevents brain lipid peroxidation when administered to rats beginning 45 minutes subsequent to $\mathrm{CO}$ poisoning. ${ }^{21}$ undersea and Hyperbaric Medical Society recommends HBO for those patients with signs of serious intoxication regardless of their COHB levels. This includes patients with a history of unconsciousness, presence of neurological signs, cardiovascular dysfunction or severe acidosis. Pregnant women should be evaluated with liberal criteria for HBO due to the increased toxicity risk to the fetus. ${ }^{1}$

Journal of Evolution of Medical and Dental Sciences/Volume1/Issue5/November-2012Page-895 
GAS GANGRENE: Infection with Clostridium Perfringens in devitalized tissue is the most common cause of gas gangrene. Clostridial microorganisms are anaerobes that produce local and systemic toxins. Wide surgical debridement and appropriate antibiotic therapy remain the standard treatment modality. Adjunctive HBO is known to have antibacterial and anti-toxin effects. ${ }^{22}$ case reports support combined therapy with HBO, antibiotics and surgery in these conditions, reducing need for drastic surgery and amputation. ${ }^{23}$

Rationale for treatment:

- HBO therapy induces high oxygen partial pressure in all tissues; achievable tissue oxygen levels are lethal to some obligate anaerobic bacteria such as Clostridium perfringens. ${ }^{22}$

-Anti-edema effect, causes activation of fibroblasts and macrophages, and stimulates angiogenesis. $^{22}$

The UHMS recommends that three 90 -min treatments should be given at 3.0ATA in the first $24 \mathrm{~h}$, followed by twice-daily treatments for $4-5$ days, until clinical improvement is seen. ${ }^{1}$

CRUSH INJURIES, COMPARTMENT SYNDROMES AND OTHER ACUTE TRAUMATIC PERIPHERAL ISCHEMIA'S: Acute traumatic peripheral ischemia's (ATPIs) results in progressive, self-perpetuating ischemia, edema and inadequate healing due to extravasation of intravascular fluid. There is severe damage centrally, with progressive improvement in adjacent tissues. Ischemia and edema may continue even when the primary injury is controlled. ${ }^{24}$

COMPARTMENT SYNDROME: Severe pain on passive stretching of the muscles involved decreased sensation in branches of the involved peripheral nerves and Elevated intra compartmental pressures on direct manometry are the symptoms associated with compartment syndrome.

\section{RATIONALE FOR TREATMENT:}

- HBO improves tissue oxygen tensions by increasing plasma-based oxygenation and increasing erythrocyte deformability. ${ }^{25}$

- Intermittent hyperoxia stimulates fibroblast and collagen synthesis, enabling angiogenesis, tissue repair and optimal healing. Hyperoxic vasoconstriction resolves oedema without impairing oxygen delivery, and reverses the ischaemia-oedema cycle. ${ }^{26}$

- HBO also antagonizes free-radical-associated lipid peroxidation, reducing reperfusion injury. ${ }^{21}$ Published research is limited, but a randomized controlled trial in 1996 demonstrated significant improvement in healing with HBO. ${ }^{27}$ The UHMS recommends treatment within 4-6h of injury, given at 2.0-2.5ATA at least once daily for several days, although guidelines vary depending on the type of injury.

DECOMPRESSION SICKNESS: Decompression sickness (DCS) occurs mainly when inert gas (mainly nitrogen) comes out of solution during ascent and decompression, forming bubbles in the capillaries and tissues in scuba divers. ${ }^{18}$ physical distortion, vessel occlusion, clotting and immune changes lead to symptoms such as fatigue, joint pains, rash, neurological and cardiorespiratory symptoms, coma and death . Predisposing factors include dehydration, injury, exertion at depth and cold exposure. ${ }^{28}$ since 1930 , HBO is the only established lifesaving treatment for DCS. 29

Rationale for treatment:

Journal of Evolution of Medical and Dental Sciences/Volume1/Issue5/November-2012Page-896 
- HBO recompresses bubbles and forces gas back into solution for a more controlled ascent.

- Inert nitrogen is replaced by rapidly-metabolized oxygen, and bubbles move either to the lungs where they are excreted, or to smaller vessels where obstruction is less important, and surface tension forces eventually collapse the bubbles.

- HBO also counteracts platelet and leukocyte activation and endothelial interactions. ${ }^{30}$

UHMS recommend rapid treatment at 2.8 ATA, repeated up to ten times if symptoms persist. ${ }^{1}$

HYPERBARIC OXYGEN THERAPY IN NON-HEALING WOUNDS: Diabetic foot ulcers, nonhealing traumatic wounds, and peripheral vascular insufficiency ulcers develop in compromised hosts with local and systemic factors contributing to impairment of tissue repair. Wound healing is slowed down due to decreased collagen production, poor capillary angiogenesis, and impaired oxygen-dependent intracellular leukocyte killing.

Rationale for treatment

- HBO therapy promotes neovascularization and increases endothelial cells, fibroblast proliferation and collagen deposition. ${ }^{31}$

- Modifies the cellular functions of the activated neutrophil, resulting in increased oxidative microbial killing and decreased neutrophil-endothelial adhesion. ${ }^{32}$

- HBO up-regulates platelet-derived growth factor receptor messenger RNA activity. ${ }^{33}$

- Has synergistic effect with growth factor. ${ }^{34}$

Kalani found that the wound-healing rate was $76 \%$ in the group with HBO therapy and $48 \%$ in the group without HBO therapy in 38 patients treated for diabetic foot ulcers over a period of three years. ${ }^{35}$ Patients are generally treated at 2.0 to 2.5 ATA for 90-120 minutes per day and receive 20-30 treatments. 35

EXCEPTIONAL BLOOD LOSS ANEMIA: Severe hemorrhagic shock and blood loss anemia may lead to tissue hypoxia and ischemia. Where whole blood transfusion is not possible, for religious or practical reasons, HBO may compensate for such a hemoglobin deficiency. HBO is used as a short-term measure, but is inconvenient and expensive, and the risk of oxygen toxicity limits its treatment.

Rationale for treatment:

HBO increases levels of plasma-dissolved oxygen to enable oxygenation while erythrocyte regeneration occurs. ${ }^{36}$

Hart described $70 \%$ survival in 26 patients who received HBO after losing $>50 \%$ of their circulating volume. ${ }^{37}$

UHMS recommend treatments at up to 3ATA for $2-4 \mathrm{~h}$ periods, three or four times a day, until hypoxic symptoms have resolved and red blood cells have been regenerated. ${ }^{1}$

INTRACRANIAL ABSCESS: HBO can be used as an adjuvant therapy in patients with severe infection or immune compromise, who may be unresponsive to standard aspiration and antibiotic treatment. ${ }^{1}$

Rationale for treatment

- $\quad$ HBO inhibits the predominantly anaerobic micro-organisms. ${ }^{20}$

- $\quad$ reduces cerebral oedema.20

Journal of Evolution of Medical and Dental Sciences/Volume1/Issue5/November-2012Page-897 
- $\quad$ modifies the immune response.20

Kurschel reported HBO therapy to be safe and effective in treating children with brain abscesses. ${ }^{37}$

UHMS recommends HBO for multiple, deep or dominantly-located abscesses, or in patients with immune compromise, poor surgical risk, or resistance to conventional treatment. ${ }^{1}$ Treatments are once or twice daily, at 2.0-2.5ATA for $60-90 \mathrm{~min}$. The average number of treatments is thirteen, and a utilization review is recommended after 20treatments. ${ }^{1}$

NECROTISING SOFT TISSUE INFECTIONS: Necrotising fasciitis is commonly seen in patients with diabetes mellitus, cirrhosis, and intravenous drug abuse. Reports of mortality range from $30 \%$ to $75 \%{ }^{1}$ It is a rapidly-progressive traumatic bacterial infection of the deep fascia with secondary subcutaneous and cutaneous involvement. Hemolytic streptococci are typical pathogens, but polymicrobial infection, host diabetes and vascular disease are all common. An obliterative endarteritis occurs, causing tissues to become hypoxic, hypovascular and hypocellular. Leukocytes become sequestered in vessels, impairing local immunity, and incomplete substrate oxidation results in hydrogen and methane accumulation in the tissues. Tissue necrosis occurs, with purulent discharge and gas production. ${ }^{1}$

Rationale for treatment

- In animal studies, HBO has a direct bactericidal effect.

- Improves tissue oxygen tension, leukocyte function and bacterial clearance. ${ }^{38}$

- Integrin inhibition decreases leukocyte adherence, reducing systemic toxicity. ${ }^{21}$

HBO has been reported to reduce mortality by up to two-thirds. ${ }^{39} \mathrm{HBO}$ is particularly indicated in bacterial gangrene and non-clostridial myonecrosis (which have high mortality and morbidity), and in compromised or unresponsive hosts. ${ }^{40}$

The UHMS recommends twice-daily treatments for $90-120 \mathrm{~min}$ at $2.0-2.5 \mathrm{ATA}$, reduced to once daily when the patient's condition is stabilized. Further treatments may be given to reduce relapse, and a utilization review is recommended after 30 treatments. ${ }^{1}$

HYPERBARIC OXYGEN AS ADJUNCTIVE THERAPY FOR OSTEOMYELITIS: Bone infections that fail to respond to surgical and antibiotic therapy due to systemic host and local immune compromised factors lead to refractory osteomyelitis. Failure of treatment or recurrence of osteomyelitis often leads to amputation. Hyperbaric oxygen can be used as an adjunctive treatment in chronic refractory osteomyelitis along with culture-directed antibiotics, surgical debridement, and nutritional support.

Rationale for treatment:

- HBO enhances oxygen-dependent leukocyte killing through the production of hydrogen peroxide and superoxide by providing increased oxygen tension in the hypoxic tissue.

- Transient reversal of hypoxia might increase clearance of bacteria. ${ }^{31}$

- Optimal tissue oxygen tension enhances osteogenesis and neovascularization. ${ }^{41}$

- HBO has also been shown to enhance osteoaclastic activity on necrotic dead bone to remove bony debris. ${ }^{42}$

- Synergistic effects of HBO on bone healing with bone morphogenic protein were also demonstrated .43

Journal of Evolution of Medical and Dental Sciences/Volume1/Issue5/November-2012Page-898 
- potentiate the antimicrobial effects of aminoglycosides, and possibly sulpha drugs and vancomycin, in the killing of susceptible bacteria. ${ }^{38}$

The results of multiple clinical studies have suggested a beneficial effect with the addition of adjunctive hyperbaric oxygen therapy to conventional treatment regimens for osteomyelitis in terms of reduced hospital stay and amputation rates. ${ }^{44}$ whereas other clinical studies have failed to demonstrate such a benefit.45Patients with osteomyelitis are usually treated at 2.0 to 2.5 ATA for 90-120 minutes per day and typically receive 20-40 treatments. ${ }^{1}$

SKIN FLAPS AND GRAFTS (COMPROMISED): Skin grafts survive as oxygen and nutrients diffuse into them from the underlying wound bed. Long-term survival depends on a new blood supply forming from the wound to the graft. When the wound bed does not have enough oxygen supplied to it, the skin graft will at least partially fail. Common causes for this are previous radiation to the wound area, diabetes mellitus, and certain infections. Significant improvements with HBO in skin grafts and flaps have been reported since 1967.46

Rationale for treatment:

- Increased angiogenesis, healing and increased microvasculature. ${ }^{47}$

- Reduce endothelial leukocyte adherence..$^{25}$

- Prevents progressive vasoconstriction of reperfusion injury. ${ }^{25}$

- Fibroblast stimulation and collagen synthesis.

Nemiroff reported significantly increased microvasculature in animals treated with HBO.47 The UHMS recommends twice-daily treatment at 2.0-2.5 ATA for 90-120min, reducing to once-daily when the graft or flap has stabilized. A utilization review is recommended after 20 treatments, whether preparing a site for grafting, or maximizing survival of a new graft. ${ }^{1}$

ACUTE THERMAL BURN INJURY: Insufficient oxygen and nutrient supply from the surrounding tissues lead to a central zone of coagulation in cases of severe burn. Burn therapy comprises respiratory care, antibiotics, debridement, and parenteral nutrition, with the aims of reducing oedema, preserving borderline tissue and enhancing host defenses.

Rationale for treatment:

- Reduces haemoconcentration, coagulability and vascular damage in thermal burns. ${ }^{48}$

- Hyperoxic vasoconstriction decreases edema, and increases collagen formation and angiogenesis. ${ }^{25}$

- Phagocytic bacterial killing is also improved, and white cell endothelial adherence is inhibited, preventing capillary damage. ${ }^{25}$

- HBO maintains ATP levels and microvascular integrity, and reduces infection. ${ }^{25}$

HBO has been proved effective in such cases and decreases healing time and reduces need for grafting. ${ }^{1}$ However, some studies have found no benefit from HBO in thermal burns and stated that HBO could worsen pulmonary damage in thermal burns. ${ }^{49}$ however clinical data is needed to further confirm the benefits. The UHMS recommends three sessions within $24 \mathrm{~h}$ of injury, and 90-min treatments twice-daily thereafter, at 2.0-2.4 ATA. ${ }^{1}$

IDIOPATHIC SUDDEN SENSORINEURAL HEARING LOSS: Idiopathic sudden sensorineural hearing loss leads to Tinnitus and a feeling of increased pressure; vertigo is less commonly

Journal of Evolution of Medical and Dental Sciences/Volume1/Issue5/November-2012Page-899 
associated with the syndrome.50Etiology could be a viral infection, such as mumps, trauma, Ménière's disease, acoustic neurinoma, ototoxic medication, multiple sclerosis vascular occlusion, viral infections, labyrinthine membrane breaks, immune associated disease, abnormal cochlear stress response, trauma, abnormal tissue growth, toxins, ototoxic drugs and cochlear membrane damage.

Rationale for treatment:

- Increase of oxygen partial pressure in the inner ear. ${ }^{51}$

-HBO restores the arterial-perilymphatic oxygen concentration difference.

A meta-analysis by Lamm showed a positive effect of $\mathrm{HBO}$ in approximately $50 \%$ of cases, after failure of classical drug therapy. ${ }^{52}$ The UHMS recommends $100 \% 02$ at 2.0 to 2.5 atmospheres absolute for 90 minutes daily for 10 to 20 treatments. $^{1}$

\section{OTHER IMPLICATIONS FOR HBO}

\section{NEUROLOGICAL ILLNESSES}

CEREBROVASCULAR ACCIDENTS (STROKE): Hyperbaric oxygen therapy shows a striking reduction in spasticity possibly due to improved function of neurons in affected areas of the brain and secondly to rise of $\mathrm{PO} 2$ in the spastic inactive and hypoxic muscle. Additionally there is an improvement in the cognitive and mental performance. ${ }^{53}$

Potential benefits:

- Increased oxygen delivery.

- decreased cerebral edema.

- decreased lipid peroxidation.

- Inhibition of leukocyte activation.

- Maintenance of blood-brain barrier integrity. ${ }^{21,54}$.

ACUTE TRAUMATIC BRAIN INJURIES: Acute traumatic brain injury causes a cycle of ischemia, hypoxia, edema and enzymatic derangements. HBO tends to break this vicious cycle. However there has to be a responsive cerebral circulation.

Rationale for treatment

- Improved aerobic metabolism,

- Reduction in lactate levels,

- Increase in creatinine phosphate and ATP levels.

- Elevation of partial pressure of Oxygen increases the diffusion distance, and 02 delivery in abnormal areas is enhanced. ${ }^{21}$

Wang demonstrated that multiple HBOT (3 ATA hourly for 3 or 5 days), delivered 2 days postinjury resulted in significantly reduced overall neurological deficit scores and neuronal apoptosis within brain tissue. 55

CEREBRAL PALSY: Studies show that HBO therapy can improve some cerebral Palsy symptoms like spasticity, vision, hearing, and speech. ${ }^{56}$ however there is a lack of clinical evidence for its use and hence HBO can be used as an adjuvant with other treatment modalities, but it is not a cure. 
The rationale for treatment:

- Increased oxygenation of the cerebral ischaemic penumbra. ${ }^{57}$

A study conducted by Collett showed improvement in gross motor function, improved performance in activities of daily living, attention, working memory, and speech in 111 children's with cerebral palsy aged 3-12 years treated with $100 \%$ oxygen at 1.75 atmospheres absolute (ATA). ${ }^{58}$

BELL'S PALSY: Steroids and surgical decompression are the only treatment used currently but results are inconclusive as to their benefit. HBO added to other treatment increases the efficacy of the treatment and reduces the period needed for restoration of complete function of the damaged nerve. 59

Rationale for treatment:

The antioedematous effect and additional oxygenation of hypoxic cranial nerve VII with dissolved oxygen. ${ }^{60}$

In the double blind study, Raeiae in $95.2 \%$ cases had full recovery in the average period of 22 days at experimental group of 42 patients treated only with HBO2 under 2.8 ATA and placebo tablets.

ONCOLOGY: A dominant feature of post-radiation change is the obliteration of small blood vessels leading to hypoxia. The oxygen tension inside a tumor drops lower as the tumor enlarges and may drop to zero in the necrotic center of the tumor. Hypoxia increases the resistance of cancer to radiotherapy. With oxygen tension at zero, the amount of radiation required to be effective is three times that required with normal oxygen tension. When irradiation is done immediately after HBO therapy, the well-oxygenated cells will be damaged lethally.

Rationale:

- Stimulates angiogenesis, increases neovascularization, fibroblast and osteoblast proliferation.

- It stimulates collagen formation at wound edges and thus helps in re-epithelialization of ulcers and provides a better nutritive bed to support grafts and pedicle flaps. ${ }^{61}$

AUTISM: Studies have shown that there is cerebral hypo perfusion in approximately $86 \%$ of autistic patients. ${ }^{62}$ Hypoperfusion could be the result of inflammation around the blood vessels in the brain. HBO is used in successful treatment of vasculitis.

Rationale for treatment:

HBO attenuates the production of proinflammatory cytokines including TNF $\alpha,{ }^{62}$ IL-1 $\beta$ and IL- 6 and increase the production of anti-inflammatory IL-10.63In one case report Heuser treated a 4 year patient with autism using $\mathrm{HBO}$ at 1.3 atm and $24 \%$ oxygen and reported striking improvement in behavior including memory and cognitive functions. 64

SIDE EFFECTS OF HBO2:While HBO2 has an admirable safety record, those recommending HBO2 in wound care should be aware of potential side effects and complications.

Journal of Evolution of Medical and Dental Sciences/Volume1/Issue5/November-2012Page-901 
EAR AND SINUS BAROTRAUMA: Middle ear barotrauma is the most common side effect of HBO2. Patients with a cold, upper respiratory tract infection or allergic rhinitis are not suitable candidates for $\mathrm{HBO} 2.65$

MYOPIA: Some patients receiving HBO2 will develop reversible myopia. ${ }^{66} \mathrm{HBO} 2$ may lead to oxidative change of the lens proteins. After cessation of therapy, the refraction usually returns to the pretreatment state within a few weeks. ${ }^{67}$

AGGRAVATION OF CONGESTIVE HEART FAILURE: HBO2 causes increased peripheral vascular resistance from its vasoconstrictive effects. Blood flow to the left ventricle has been noted to decrease during HBO. Patients with a cardiac ejection fraction of less than $35 \%$ are generally not treated by HBO. 68

PULMONARY BAROTRAUMA: injury is related to pressure changes and occurs only on ascent. For the lungs to be injured there must be an obstruction such as a closed glottis or bronchial obstruction. An untreated pneumothorax is an absolute contradiction to HBO2 therapy and patients with a pneumothorax must have a chest tube inserted prior to the treatment dive. If a pneumothorax occurs during the treatment, a chest tube must be inserted prior to ascent to prevent a marked deterioration in the condition of the patient. 69

COST: analysis has shown that the addition of hyperbaric oxygen to conventional treatment results in significant cost savings due to lesser stay in hospital and shorter course of illness. ${ }^{53}$

CONCLUSION: The Hyperbaric Committee of the Undersea and Hyperbaric Medical Society in the US (UHMS) reviews and publishes once in 2-3 years the indications for HBO, which are supported by adequate medical literature. The Committee usually looks for three kinds of evidence: physiological, animal studies and human studies preferably double blinded, and publishes this list of "approved" indications. In addition to the use of HBO for the "Approved" indications, growth of Hyperbaric Medicine over the past two decades has also led to its popularity and use for some "unapproved" or the so called "Off Label" indications. In diseases for which the use of hyperbaric oxygen is not well supported, the potential benefits must be carefully weighed against the risks of treating. Patient selection for HBOT should be executed carefully and according to accepted guidelines. If safety guidelines are strictly followed, HBO therapy is a modality with an acceptable rate of complications. Doctors in all fields must familiarize themselves with recent evidence on this mode of therapy, so that their patients are not denied the gains of this modern treatment.

\section{REFERENCE:}

1. Hampson NB, ed. Hyperbaric Oxygen Therapy: 1999 Committee report. Kensington MD, Undersea and Hyperbaric Medical Society, 1999.

2. Leach RM, Rees PJ, Wilmshurst P. Hyperbaric oxygen therapy.BMJ 1998; 317:1140-3.

3. Simpson A. Compressed air as a therapeutic agent in the treatment of consumption, asthma, chronic bronchitis and other diseases. Edinburgh: Sutherland and Knox, 1857. 
4. Acott, C. (1999). "JS Haldane, JBS Haldane, L Hill, and A Siebe: A brief resume of their lives."South Pacific Underwater Medicine Society Journal 29 (3). ISSN 08131988. OCLC 16986801.Retrieved 2008-07-12.

5. Kindwall EP, Gottlieb FJ, Larson DL. Hyperbaric oxygen therapy in plastic surgery, plastic and reconstructive therapy.1991; 888:898-908.

6. Hart GB. The monoplace chamber. In: Kindwall EP, ed. hyperbaric medicine practice. Flagstaff, Ariz.: Best,1994:57-82.

7. National Fire Protection Association: NFPA 99: Standard for Health Care Facilities. 2005 Edition.Quincy, MA, NFPA, 2005.

8. Sheffield PJ, Desautels DA: Hyperbaric and hypobaric chamber fires: A 73-year analysis. Undersea Hyperb Med 1997; 24:153-164.

9. Gossett WA, Rockswold GL, Rockswold SB: The safe treatment, monitoring and management of severe traumatic brain injury patients in a monoplace chamber. Undersea Hyperb Med 2010; 37:35-48

10. Weaver LK, Churchill SC, Bell JE: Taking the chamber to the critically ill patient. Abstr. Undersea Hyperb Med 2010; 37:347

11. Waydhas C, Schneck G, Duswald KH: Deterioration of respiratory function after intrahospital transport of critically ill surgical patients. Intensive Care Med 1995; 21:784-789.

12. Shirley PJ, Bion JF: Intra-hospital transport of critically ill patients: Minimising risk. Intensive Care Med 2004; 30:1508-1510.

13. Murphy BP, Harford FJ, Cramer FS. Cerebral air embolism resulting from invasive medical procedures: treatment with hyperbaric oxygen. Ann Surg 1985; 201:242-5.

14. Muth CM, Shank ES. Gas embolism. N Engl J Med 2000; 342:476-82.

15. Branger $A B$, Lambertsen CJ, Eckmann DM. Cerebral gas embolism absorption during hyperbaric therapy: theory. J ApplPhysiol 2001; 90:593-600.

16. Dexter F, Hindman BJ. Recommendations for hyperbaric oxygen therapy of cerebral air embolism based on a mathematical model of bubble absorption.AnesthAnalg 1997; 84:1203-7.

17. Moon RE, de Lisle Dear G, Stolp BW. Treatment of decompression illness and iatrogenic gas embolism.Respir Care Clin N Am 1999; 5:93-135.

18. Benson J, Adkinson C, Collier R. Hyperbaric oxygen therapy of iatrogenic cerebral arterial gas embolism. Undersea Hyperb Med 2003; 30:117-26.

19. Gosselin RE, Smith RP, Hodge HC, eds. Clinical Toxicology of Commercial Products, 4th edn, Baltimore, MD: Williams and Wilkins, 1984

20. Tibbles PM, Edelsberg JS. Hyperbaric oxygen therapy (Reviewarticle). NEJM 1996:1642-8.

21. Thom SR. Dehydrogenase conversion to oxidase and lipid peroxidation in brain after carbon monoxide poisoning. J ApplPhysiol 1992;73:1584-9.

22. Kaye D. Effect of hyperbaric oxygen on Clostridia in vitro and in vivo. ProcSocExpBiol Med 1967; 124:360-6.

23. Hirn M. Hyperbaric oxygen in the treatment of gas gangrene and perineal necrotizing fasciitis.Eur J Surg 1993; 570:1-36.

24. Wattel F, Mathieu D. Proceedings of the 1st European Consensus Conference on Hyperbaric Medicine. Lille (France), 1994:377-82.

25. Zamboni WA, Roth AC, Russell RC, Graham B, Suchy H, Kucan JO et al. Morphological analysis of the microcirculation during reperfusion of ischaemic 
skeletal muscle and the effect of hyperbaric oxygen. Plastic ReconstrSurg 1993; 91:1110-23.

26. Nylander G, Lewis D, Lewis D. Reduction of post-ischaemicoedema with hyperbaric oxygen. PlastReconstrSurg 1985; 76:596-601.

27. Bouachour G, Cronier P, Gouello JP. Hyperbaric oxygen therapy in the management of crush injuries: a randomised double-blind placebo-controlled trial. J Trauma 1996; 41:333-9.

28. Hagberg $M$, Ornhagen $H$. Incidence and risk factors for symptoms of decompression sickness among male and female dive masters and instructors: a retrospective cohort study. Undersea Hyperb Med 2003; 30:93-102.

29. Yarbrough OD, Behnke AR. Treatment of compressed air illness utilizing oxygen. J IndustHygToxicol 1939; 21:213-18.

30. Ishii Y, Miyanaga Y, Shimojo H, Ushida T, Tateishi T. Effects of hyperbaric oxygen on procollagen messenger RNA levels and collagen synthesis in the healing of rat tendon laceration. Tissue Eng 1999;5: 279-86.

31. Knighton DR, Halliday B, Hunt TK. Oxygen as an antibiotic. The effect of inspired oxygen on infection. Arch Surg 1984;119:199-204

32. Bonomo SR, Davidson JD, Tyrone JW, Lin X, Mustoe TA.Enhancement of wound healing by hyperbaric oxygen and transforming growth factor beta3 in a new chronic wound model in aged rabbits. Arch Surg 2000; 135:1148-53.

33. Zhao LL, Davidson JD, Wee SC, Roth SI, Mustoe TA.Effect of hyperbaric oxygen and growth factors on rabbit ear ischemic ulcers. Arch Surg 1994;129:1043-9.

34. Kalani M, Jorneskog G, Naderi N, Lind F, Brismar K. Hyperbaric oxygen therapy in treatment of diabetic foot ulcers. Long-term follow-up. J Diabetes 2002; 16:1538.

35. Gill, Bell CN. Hyperbaric oxygen: its uses, mechanisms of action and outcomes. QJM. 2004 Jul;97(7):385-95.

36. Hart GB, Lamb RC, Strauss MB. Gas gangrene. J Trauma 1983; 23: 991-100.

37. Kurschel S, Mohia A, Weigl V, Eder HG. Hyperbaric oxygen therapy for the treatment of brain abscess in children. Childs Nerv Syst. 2006 Jan;22(1):38-42.

38. Mader JT, Guckian JC, Glass DL, Reinarz JA.Therapy with hyperbaric oxygen for experimental osteomyelitis due to Staphylococcus aureus in rabbits. J Infect Dis 1978; 138:312-18.

39. Riseman JA, Zamboni WA, Curtis A, Graham DR, Konrad HR, Ross DS et al. Hyperbaric oxygen therapy for necrotizing fasciitis reduces mortality and the need for debridements. Surgery 1990; 108:847-50.

40. Hirn M, Niinikoski J, Lehtonen OP. Effect of hyperbaric oxygen and surgery on experimental multimicrobial gas gangrene. EurSurg Res 1993; 25:265-9.

41. Sheikh AY, Gibson JJ, Rollins MD, Hopf HW, Hussain Z, Hunt TK et al. Effect of hyperoxia on vascular endothelial growth factor levels in a wound model. Arch Surg 2000; 135:1293-7.

42. Barth E, Sullivan T, Berg E. Animal model for evaluating bone repair with and without adjunctive hyperbaric oxygen therapy (HBO): comparing dose schedules. J Invest Surg 1990;3:387-92.

43. Okubo Y, Bessho K, Fujimura K, Kusumoto K, Ogawa Y, Iizuka T et al. Effect of hyperbaric oxygenation on bone induced by recombinant human bone morphogenetic protein-2. Br J Oral MaxillofacSurg 2001;39:91-5 
44. Davis JC, Heckman JD, DeLee JC, Buckwold FJ. Chronic non-haematogenous osteomyelitis treated with adjuvant hyperbaric oxygen. J Bone Joint Surg 1986;68A:1210-7.

45. Esterhai JL Jr, Pisarello J, Brighton CT, Heppenstall RB, Gellman H, Goldstein G et al. Adjunctive hyperbaric oxygen therapy in the treatment of chronic refractory osteomyelitis. J Trauma 1987;27:763-8.

46. Perrins DJD. Influence of hyperbaric oxygen on the survival of split skin grafts. Lancet 1967; 7495:868-71.

47. Nemiroff PM, Lungu AL. The influence of hyperbaric oxygen and irradiation on vascularity in skin flaps: a controlled study. Surg Forum 1987; 38:565-7.

48. Grossman AR, Grossman AJ. Update on hyperbaric oxygen and treatment of burns. Burns 1982; 8:176-9.

49. Brannen AL, Still J, Haynes M, Orlet H, Rosenblum F, Law E, et al. A randomised prospective trial of hyperbaric oxygen in a referral burn centre population. Ann Surg 1997; 63:205-8.

50. Lehnhardt, R.E. Die akuteInnenohrschwerhörigkeit. HNO 1991; 39: 378-385

51. Murata, K. and U. Fisch. Effect of CO2 on the perilymphatic oxygen tension in cats. Ann OtolRhinolLaryngol 1977; 86: 164-171

52. Lamm, K., Lamm, H. and W. Arnold. Effect of hyperbaric oxygen therapy in comparison to conventional or placebo therapy or no treatment in idiopathic sudden hearing loss, acoustic trauma, noise-induced hearing loss and tinnitus.A literature survey.AdvOtorhinolaryngol. 1998;54:86-99.

53. Sahni T, Jain M. Status of Status of Hyperbaric Oxygen Therapy in Neurological Illnesses - Review of International and Indian experience. Neurosciences Today 2003; 7:126-134.

54. Mink RB, Dutka AJ. Hyperbaric oxygen after global cerebral ischemia in rabbits reduces brain vascular permeability and blood flow. Stroke. 1995; 26: 23072312

55. Wang GH, Zhang XG, Jiang ZL, Li X, Peng LL, Li YC et al.: Neuroprotective Effects of Hyperbaric Oxygen Treatment on Traumatic Brain Injury in the Rat. J Neurotrauma 2010, 27:1733-1743

56. Montgomery D, Goldberg J, Amar M. Effects of hyperbaric oxygen therapy on children with spastic diplegic cerebral palsy: A pilot project. Undersea Hyperb Med 1999;26:235-42.

57. Neubauer RA. Hyperbaric oxygen for treatment of closed head injury. South Med J 1994;87:933-6.

58. Collet JP, Vanasse M. Hyperbaric oxygen for children with cerebral palsy; a randomized multicentre trial. HBO-CP Research Group. Lancet 2001;357:582-86.

59. Heiden $\mathrm{CH}$, Biesinger E, Hoing R. Idiopathic facial palsy (Bell's Palsy): an indication for hyperbaric oxygen therapy? Eur J Underwater Hyper baric Med 2003; 4(1): 20-23.

60. Raèiæ G, Denoble P, Sprem N, Bojiæ L, Bota B. Hyperbaric Oxygen as therapy of Bell,s palsy. Undersea Hyperb Med 1997; 24(1):35-8.

61. TarunSahni, Madhur Jain, S. Hukku, G.K. Jadhav. Role of hyperbaric oxygen therapy in oncology and radiation induced tissue damage: Apollo Medicine, Vol.1, December 2004

62. Weisz G, Lavy A, Adir Y, Melamed Y, Rubin D, Eidelman S, Pollack S et al. Modification of in vivo and in vitro TNF-alpha, IL-1, and IL-6 secretion by 
circulating monocytes during hyperbaric oxygen treatment in patients with perianal Crohn's disease. J ClinImmunol. 1997 Mar;17(2):154-9.

63. Benson RM, Minter LM, Osborne BA, Granowitz EV. Hyperbaric oxygen inhibits stimulus-induced proinflammatory cytokine synthesis by human blood-derived monocyte-macrophages. ClinExpImmunol. 2003 Oct;134(1):57-62.

64. G Heuser, SA Heuser, D Rodelander Treatment of neurologically impaired adults and children with mild hyperbaric oxygen (1.38 ATA and $24 \%$ oxygen) edited by Joiner JT Flagstaff Arizona:best publications 2002:109-15.

65. Plafki C, Peters P, Almeling M, Welslau W, Busch R. Complications and side effects of hyperbaric oxygen therapy. Aviat Space Environ Med 2000; 71(2): 119-24.

66. Palmquist BM, Philipson B, Barr PO. Nuclear cataract and myopia during hyperbaric oxygen therapy. Br J Ophthalmol 1984; 68(2): 113-7.

67. Lyne AJ. Ocular effects of hyperbaric oxygen. Trans OphthalmolSoc UK 1978; 98(1): 66-8.

68. Bergo GW, Risberg J, Tyssebotn I. Effect of 5 bar oxygen on cardiac output and organ blood flow in conscious rats. Undersea Biomed Res 1988; 15(6): 457-70.

69. Davis JC, Dunn JM, Heimbach RD. Hyperbaric medicine: Patient selection, treatment procedures and side effects. In: Davis JC, Hunt TK, editors. Problem Wounds - the role of oxygen. New York: Elsevier, 1988. 